\title{
N/P ratio of nutrient uptake in the Baltic Sea
}

\author{
Z. Wan ${ }^{1}$, L. Jonasson ${ }^{1}$, and H. Bi ${ }^{2}$ \\ ${ }^{1}$ Centre for Ocean and Ice, Danish Meteorological Institute, Lyngbyvey 100, 2100 Copenhagen, Denmark \\ ${ }^{2}$ Chesapeake Biological Laboratory, P.O. Box 38, Solomons, MD 20688, USA
}

Received: 5 March 2011 - Published in Ocean Sci. Discuss.: 10 June 2011

Revised: 12 October 2011 - Accepted: 20 October 2011 - Published: 31 October 2011

\begin{abstract}
The N/P ratio of nutrient uptake, the change of dissolved inorganic nitrogen (DIN) relative to the change of dissolved inorganic phosphorus (DIP), is a key parameter for many ecological models. In the Baltic Sea ecosystem, the N/P ratio of nutrient uptake varies among different basins and different seasons. The N/P ratio of nutrient alteration, i.e., the ratio of DIN to DIP altered before and after spring blooms, is not the same as the N/P ratio of nutrient uptake, but the former can be regarded as an indicator of the latter in the Baltic Sea. Based on the observed N/P ratio of nutrient alteration, we hypothesize a non-Redfield N/P ratio of nutrient uptake. The 3-D-ecosystem model ERGOM coupled with the circulation model DMI-BSHcmod was used to test this hypothesis. When the Redfield ratio was used in the model, the DIP surplus after spring blooms was too high and resulted in excessive growth of cyanobacteria and too much nitrogen fixation. When the non-Redfield ratio was used in the model, these problems tended to disappear. In summary, we show that: (1) the Redfield N/P ratio of nutrient uptake in the Baltic Sea tends to be too high; (2) a N/P ratio of 10:1 appears to work better than the Redfield value; and (3) the N/P ratio of nutrient uptake in the Baltic Proper during spring blooms is around 6:1. As the model limitation using one identical value for two N/P ratios for nutrient uptake and remineralization, the quantitative conclusions are only convincing as a model parameter even though it obviously improves model predictions. Whether this model parameter is consistent with the biological nutrient uptake is worth being further verified with some laboratory investigations or simulations using a more sophisticated model with independent N/P ratios for nutrient uptake and remineralization.
\end{abstract}

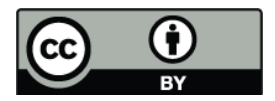

Correspondence to: Z. Wan (zw@dmi.dk)

\section{Introduction}

The N/P ratio of nutrient uptake is referred as the ratio of dissolved inorganic nitrogen (DIN) to dissolved inorganic phosphorus (DIP) taken up by primary producers during photosynthesis. The N/P ratio of nutrient uptake differs from the N/P ratio of detritus decomposition in principle. Two ratios should be close or even identical at ecosystem scales, due to the constraint of mass conservation. In ecological modeling, it is common to use one identical value for two ratios. Models which use independent values for two ratios have to add the state variables and increase the computational complication (Savchuk and Wulff, 2008; Kuznetsov et al., 2008). In case of one identical value for two processes, the model parameter named as the N/P ratio of nutrient uptake actually describes the elemental ratio of $\mathrm{N}$ to $\mathrm{P}$ in nutrient changes caused by nutrient uptake in combination with one part of labile detritus remineralization which occurs in euphotic layers. Hereafter, if it is not explicitly noted as a biological N/P ratio of nutrient uptake, a N/P ratio of nutrient uptake is meant the parameter on models which uses one identical value for nutrient uptake and remineralization. This study is focused on identifying a suitable value for this model parameter through using the observed data in combination with modelling experiements. To be clear, we define "N/P ratio of nutrient alteration" as the change of overall seawater DIN relative to the change of DIP for a certain duration.

Although we come across the N/P ratio issue in the modeling practice for operational oceanography, this issue is not treated as a parameter optimization. While we are calibrating ERGOM (Neumann, 2000; Neumann et al., 2002) with Redfield ratios, we find the modeled nutrient alteration before and after spring bloom are consistently different from the observed DIN and DIP concentrations. The discrepancy between the modeled results and observed data motivates us to take further steps to investigate whether the N/P ratio of

Published by Copernicus Publications on behalf of the European Geosciences Union. 
nutrient uptake in the Baltic Sea is consistent with the Redfield value (Redfield, 1934). We address this issue in the following steps. First, the N/P ratio of nutrients alteration before and after the spring bloom is examined with observations of multiple years. Second, the N/P ratio of nutrient changes caused by the biological pump during the spring bloom is estimated using the observed concentrations of DIN and DIP in seawater and atmospheric nutrient deposition and river nutrient discharge. Third, a 3-D physical-bigeochemical coupled model is used to test the scenarios of different N/P ratios of nutrient uptake. Fourth, whether the models using the Redfield ratio cause some characteristic model-observation biases are examined.

Many studies have showed that the N/P ratio of nutrient uptake can differ among species and life stages, which affects the biogeochemistry in many marine ecosystems (Minster and Boulahdid, 1987; Arrigo et al., 1999; Kress and Herut, 2001; Wong et al., 2002; Anderson and Pondaven, 2003). Redfield (1934) analyzed the elemental ratios of phytoplankton in the world's oceans and proposed the famous Redfield ratios, which have been widely used in ecosystem models. However, any fixed N/P ratio, Redfield or otherwise, is an oversimplification when applied to real ecosystems. In fact, some recent studies have used variable N/P ratios (Touratier et al., 2001; Moore et al., 2002; Kuznetsov et al., 2008). The Baltic Sea is characterized by strong nitrogen fixation by cyanobacteria, abundant denitrification in anoxic bottom water (Shaffer and Rønner, 1984), and variable nutrient conditions in different basins. Therefore, it remains a challenge to estimate a suitable N/P ratio for nutrient uptake in the Baltic Sea.

The N/P ratio of nutrient uptake in the Baltic Sea is often treated as consistent with the Redfield Ratios in both modeling studies (Neumann, 2000; Edelvang et al., 2005; Savchuk et al., 2008; Eilola et al., 2009) and observation-based studies (Osterroht and Thomas, 2000; Savchuk, 2005). In many cases, though not always, Redfield ratios are suitable for interpreting the spatial and temporal dynamics in nutrient concentration. For example, Osterroht and Thomas (2000) noticed that the N/P ratio of nutrient alteration before and after the growing season was much different from Redfield ratios; they explained that the elemental ratios of nutrient uptake were consistent with Redfield ratios, but the nutrients remineralized from freshly produced organic material had nonRedfield ratios. It could also be alternatively explained that the elemental ratios of nutrient uptake were inconsistent with Redfield ratios. These arguments can be mediated in terms of nutrient alteration of net biological pump effects (jointly acted by nutrient uptake and remineralzation). Other investigations have suggested that the elemental ratios of biology in the Baltic Sea could differ from the Redfield ratios (Shaffer, 1987; Larsson et al., 2001). Larsson et al. (2001) reported that the N/P ratio of nutrient uptake during cyanobacterial blooms in the Baltic Sea might be several times larger than Redfield ratios. Kuznetsov et al. (2008) modeled the ecolog- ical effect of a variable $\mathrm{C}: \mathrm{N}: \mathrm{P}$ ratio for cyanobacteria, based on the findings of Larsson et al. (2001).

\section{Methods}

\subsection{Physical model}

The physical model in this study is the Danish Meteorological Institute (DMI) operational model DMI-BSHcmod, which was originally developed by the German Bundesamt fuer Seeschifffahrt und Hydrographie (BSH) (Dick et al., 2001). The core of the physical model, a circulation model, is based on the primitive geophysical fluid dynamics equations for the conservations of volume, momentum, salinity, and heat. The thermodynamic model component is able to resolve the ice dynamics, as well as the reflection and absorption of shortwave radiation by the seabed in shallow zones. The impacts from wind, atmospheric pressure, air temperature, humidity, evaporation-precipitation, and cloud cover are all considered and parameterized as boundary conditions. The tidal water level and the monthly climatologies of temperature and salinity are imposed as the outer lateral conditions, and the river runoffs as the inner lateral condition. The operational implementation of the circulation model started at BSH in the mid-1990s and has been further developed at DMI since 2001.

The model grids cover the area from $48^{\circ} 33^{\prime} \mathrm{N}$ to $65^{\circ} 51^{\prime} \mathrm{N}$ and from $4^{\circ} 05^{\prime} \mathrm{W}$ to $30^{\circ} 15^{\prime} \mathrm{E}$ with a horizontal resolution of $6^{\prime}$ latitude and $10^{\prime}$ longitude, while a nested fine grid with one sixth of the coarse resolution covers the Danish Strait in order to resolve the water exchange through the narrow sills between the North Sea and the Baltic Sea. The coarse grid has 50 vertical layers: an $8 \mathrm{~m}$ surface layer, to avoid drying at low tides, followed by $2 \mathrm{~m}$ subsurface layers $(n=36)$, and $4 \mathrm{~m}(n=1), 8 \mathrm{~m}(n=2), 25 \mathrm{~m}(n=2)$ and $50 \mathrm{~m}(n=8)$. The fine grid has 52 vertical layers, with thicknesses of $2 \mathrm{~m}$ (surface), $1 \mathrm{~m}(n=29)$ and $2 \mathrm{~m}$ (all others). The model domain includes both the Baltic Sea and the North Sea (Fig. 1) in order to supply a sufficient transition to counteract the effects from open boundaries.

The model is driven by hourly meteorological forcing ( $10 \mathrm{~m}$ winds, $2 \mathrm{~m}$ air temperature, mean sea level pressure, surface humidity, and cloud cover) based on DMI's version of the operational weather model HIRLAM (High Resolution Limited Area Model). The weather model has a horizontal resolution of about $15 \mathrm{~km}$. River runoff is set with the daily averaged data derived from river measurements for 5 German rivers, operational outputs for 43 Baltic catchments by a hydrological model HBV run by the Swedish Meteorological Hydrological Institute (SMHI) (Bergström, 1976 and 1992), and climatology for the remaining rivers. The configuration and performance of DMI-BSHcmod have been reported previously (She et al., 2007a, b; Larsen et al., 2007; Liu et al., 2009). 


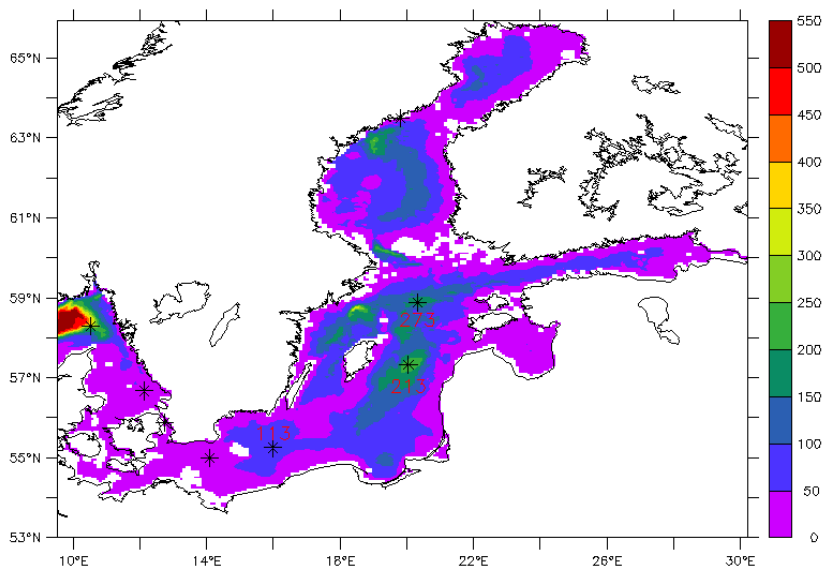

Fig. 1. Bathymetry of the Baltic Sea (unit: m) and locations of selected observation stations. Data from stations $(*)$ are used for Table 2. Time-series of data are collected from Stat. 113 (Arkona Basin), Stat. 213 (Bornholm Basin), and Stat. 271 (Gotland Deep).

\subsection{Ecosystem model}

The ecosystem model ERGOM was developed by Neumann (2000). It has 9 state variables, consisting of dissolved inorganic nutrients: ammonium, nitrate and phosphate; three autotrophic functional groups: diatoms, flagellates and cyanobacteria; a bulk zooplankton community; a detritus pool; and dissolved oxygen (DO). The model mathematically describes the processes of photosynthesis, nutrient uptake, growth, grazing, digestion, respiration, excretion, mortality, remineralization, nitrogen fixation, nitrification, and denitrification. This model is nitrogen-based, and phosphorus is coupled to nitrogen via the Redfield ratio. Hydrogen sulfate is included in the model as negative oxygen concentration. A detailed model description and a list of biogeochemical parameterization coefficients can be found in Neumann (2000) and Neumann et al. (2002). We made one simplification to ERGOM by ignoring the re-suspension of sedimentary detritus. This simplification is likely to have some impact for the remineralization rate and the spatial distribution of sedimentary detritus, but does not change the model description of benthic biogeochemistry and the amount of detritus. The parameters used here and those from Neumann et al. (2002) are listed in Table 1. The parameter changes are made for model calibration in terms of algae bloom timing and total mass balance. These parameter changes have no impact to N/P ratio of nutrient uptake at seasonal scale, e.g., before and after spring bloom. For instance, as the parameter "nitrification ratio of mineralized benthic detritus" changes from 0.50 to 0.40 , the contribution of benthic detritus to DIN can be raised in all seasons, but it does not specially impact the DIN alteration before and after spring bloom.

The initial fields for ammonia, nitrate, DIP and DO are extrapolated from the winter means of data (2001-2009) at
16 off-shore long-term monitoring stations from the International Council for the Exploration of the Sea (ICES) website (http://www.ices.dk/indexfla.asp). The initial fields for biological state variables are manipulated through repetitive runs. The open boundary conditions are configured with the data from the World Ocean Atlas 2001 (WOA01, Conkright et al., 2002) for nitrate, phosphate, and DO, and the remaining state variables are set to zero. River loadings and runoffs are derived from outputs of the operational hydrological model. Atmospheric nutrient deposition values are set based on Langner et al. (2009) and Eilola et al. (2009).

\subsection{Model runs}

We made several model runs with different N/P ratios to determine which ratio most closely replicated the observed data. Three of these will be presented in detail to illustrate the effect of non-Redfield ratios: Case NP16 is the model run with N/P ratio 16:1, Case NP10 is the model run with N/P ratio 10:1 and Case NP6 is the model run with N/P ratio 6:1. All model runs use identical initial fields and forcings with parameters from Neumann et al. (2002) except as specified in Table 1. The formal model run is from 1 January 2001 to 31 December 2007. In fact, a simulation of seven years is not sufficient to fully spin up the benthic dynamics. As it mentioned before, we make several repetitive runs to generate the initial fields for biological state variables.

\subsection{Data}

The data used to validate model and to analyze the N/P ratio of nutrient alteration were downloaded from the ICES website. ICES is a free-access database that contains data from different sources, including in-situ measurements from automated monitoring instruments and those of water samplers either from cruises or from fixed stations.

The data used to analyze the N/P ratio of nutrient alteration are monthly time series of observations from eight fixed stations (Table 2). We interpolate the monthly time series of observations onto the preset dates at first, and then calculate the N/P ratio of nutrient alteration using the mean values before and after spring bloom. Testing the data from different dates within the same month, the resulting N/P ratio of nutrient alteration did not differ much. Thus, we chose 1 February as the date representing the average winter state before spring blooms and 1 June as the date representative of summer conditions. Table 2 lists the mean values in years 2001-2007 for DIN, DIP before and after spring blooms and the N/P ratio of nutrient alteration in the surface layer at eight fixed stations.

The data on seasonal variability, used for comparison with seasonal patterns of model results, are from three fixed stations in the Baltic Proper: Stat. 113 in Arkona Basin, Stat. 213 in Bornholm Basin and Stat. 271 Gotland Deep (Fig. 1). The surface values of Chl- $a$, DIN and DIP are from 2005 to 2007. 
Table 1. Parameter values used in this study and those used by Neumann et al. (2002)

\begin{tabular}{lll}
\hline Parameter & $\begin{array}{l}\text { Value } \\
\text { This manuscript }\end{array}$ & $\begin{array}{l}\text { Value } \\
\text { Neumann et al. (2002) }\end{array}$ \\
\hline Minimum irradiance & $50 \mathrm{Wm}^{-2}$ & $25 \mathrm{Wm}^{-2}$ \\
Ivlev constant of zooplankton & 0.8 & 1.2 \\
Temperature control of cyanobacteria & $14{ }^{\circ} \mathrm{C}$ & $16^{\circ} \mathrm{C}$ \\
Redfield ratio (N/P) & 10 & 16 \\
Nitrification ratio of remineralized benthic detritus & 0.40 & 0.50 \\
Phosphorus loss of remineralized benthic detritus & 0.0 & 0.15
\end{tabular}

Table 2. N/P ratio of nutrient alteration before and after spring blooms in surface waters.

\begin{tabular}{ccccccr}
\hline $\begin{array}{c}\text { Latitude } \\
\left({ }^{\circ} \mathrm{N}\right)\end{array}$ & $\begin{array}{c}\text { Longitude } \\
\left({ }^{\circ} \mathrm{E}\right)\end{array}$ & $\begin{array}{c}\text { Before. }{ }^{*} \mathrm{DIN} \\
\left(\mathrm{mmol} \mathrm{m}^{-3}\right)\end{array}$ & $\begin{array}{c}\text { Before.DIP } \\
\left(\mathrm{mmol} \mathrm{m}^{-3}\right)\end{array}$ & $\begin{array}{c}\text { After. }{ }^{*} \mathrm{DIN} \\
\left(\mathrm{mmol} \mathrm{m}^{-3}\right)\end{array}$ & $\begin{array}{c}\text { After.DIP } \\
\left(\mathrm{mmol} \mathrm{m}^{-3}\right)\end{array}$ & N/P ratio \\
\hline 58.28 & 10.51 & 6.76 & 0.51 & 0.32 & 0.04 & $13.7: 1$ \\
56.67 & 12.12 & 6.23 & 0.56 & 0.24 & 0.06 & $12.0: 1$ \\
55.88 & 12.75 & 4.83 & 0.56 & 0.24 & 0.16 & $11.6: 1$ \\
55.00 & 14.08 & 3.15 & 0.56 & 0.21 & 0.20 & $8.3: 1$ \\
55.25 & 15.98 & 2.95 & 0.65 & 0.23 & 0.26 & $7.0: 1$ \\
57.33 & 20.05 & 3.23 & 0.62 & 0.24 & 0.11 & $6.0: 1$ \\
58.88 & 20.32 & 3.73 & 0.65 & 0.09 & 0.09 & $6.5: 1$ \\
63.50 & 19.82 & 6.50 & 0.25 & 0.40 & 0.03 & $27.7: 1$ \\
\hline
\end{tabular}

* Before. (After.) represents the mean value on 1 February (1 June) in 2001-2007. Data preparation is explained in Sect. 2.4.

The data used to assess the overall model skill include all ICES data records for Chl- $a$, DIN and DIP from $10^{\circ} \mathrm{E}-30^{\circ} \mathrm{E}$, $53^{\circ} \mathrm{N}-66^{\circ} \mathrm{N}$ in 2005 to 2007 (http://www.ices.dk/indexfla. asp). They are processed using the scheme of comprehensive validation described in the next section. The total record numbers are 7312 for Chl- $a, 16028$ for DIN, and 17302 for DIP.

\subsection{A comprehensive model validation scheme}

Model validation is usually implemented through comparing model results with observed data at selected stations or subdomains. In addition to the usual model validation methods, we use a comprehensive model validation scheme to show overall model performance. The comprehensive model validation scheme emphasizes the importance of using all available observations, and can provide an overview of model performance.

The preparation of model-observation pairs uses the following procedure. First, the model outputs are interpolated to match each observed datum, i.e., to form the preliminary model-observation pairs. Second, a 4-D spatiotemporal grid is defined to limit the data representation properly. The mean value of preliminary model-observation pairs (if more than one) in each grid is used as the secondary model-observation pair. Third, those secondary model-observation pairs with the same specified dimension(s) are further averaged to form the final model-observation pairs. The model's skill along the specified dimension(s) is presented by comparing the final model-observation pairs. Comparing modeled and observed values for all the secondary model-observation pairs ((model,observ $)_{i, j, k, l}$ ), the skill of the model for dimension $k$ is determined by comparing the mean values of (model, observ) $)_{i, j, k, l}$ averaged over $i, j, l$. In this study, the 4-D spatiotemporal grid has a horizontal resolution of $0.5 \times 0.5^{\circ}$, a vertical resolution of $4 \mathrm{~m}$, and a temporal resolution of 15 days for the area from $10^{\circ} \mathrm{E}-30^{\circ} \mathrm{E}, 53^{\circ} \mathrm{N}-66^{\circ} \mathrm{N}$ from 2005 to 2007. An example of the results of this comparison is the overall fitness between modeled and observed temporal evolution of Chl- $a$ (Fig. 3a). Each value in Fig. 3a stands for the "mean" of Chl- $a$ in the whole Baltic Sea at one specific moment. However, the "mean" is not a simple average over all observation records at that moment, but an average over the defined grids where there is at least one observation record. This comparison was also conducted for depth, with each value representing the "mean" of Chl- $a$ averaged over all observed grids at one specific depth (Fig. 3d). 


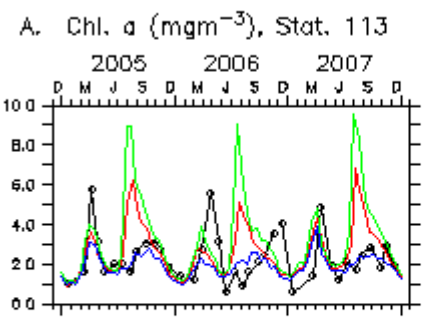

B. DIN (mmolm ${ }^{-3}$ ), stat. 113

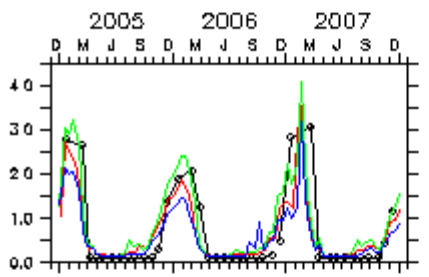

C. DIP ( $\left.\mathrm{mmolm}^{-3}\right)$, Stat 113

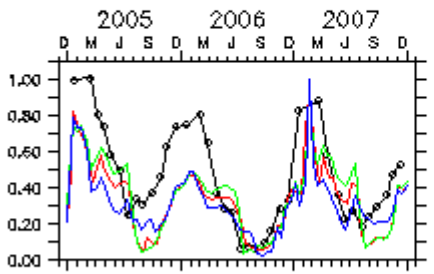

D. Chl. a $\left(\mathrm{mgm}^{-3}\right)$, Stat. 213 $2005 \quad 2006 \quad 2007$

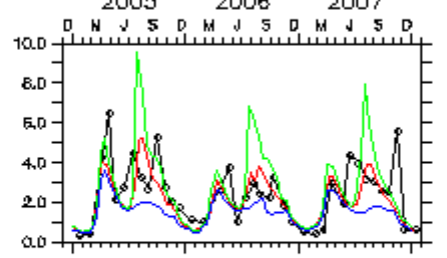

E. DIN (mmolm $\mathrm{m}^{-3}$ ), 5tat. 213 $20052006 \quad 2007$

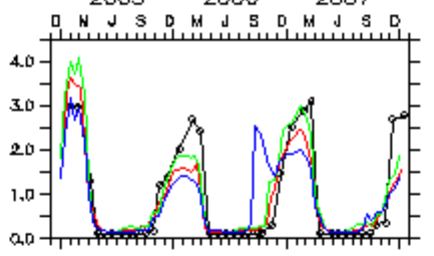

F DIP (mmolm $\left.{ }^{-3}\right)$, Stat. 213

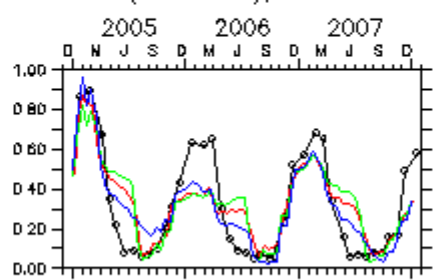

G. Chl. a $\left(\mathrm{mgm}^{-3}\right)$, stat. 271

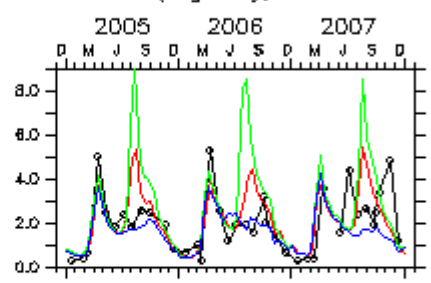

H. DIN $\left(\mathrm{mmolm}^{-3}\right)$, Stat. 271 $20052006 \quad 2007$

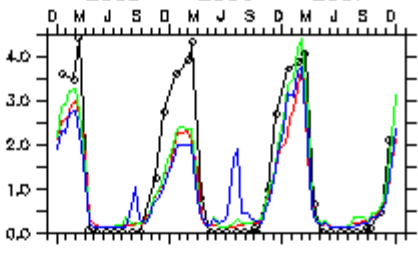

I DIP $\left(\mathrm{mmolm}^{-3}\right)$, Stat. 271

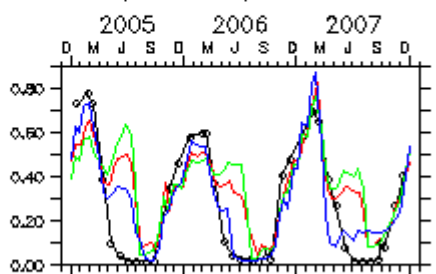

Fig. 2. Comparison of surface model results among three experiments with observed data from offshore stations. Black dashed line is observed data, solid lines show model results of Cases NP16 (green), NP10 (red), and NP6 (blue). Abbreviations: Chl- $a$ for chlorophyll- $a$, DIN for dissolved inorganic nitrogen, DIP for dissolved inorganic phosphorus, and Stat. 113 (Arkona Basin), Stat. 213 (Bornholm Basin), and Stat. 271 (Gotland Deep) (locations in Fig. 1).

\section{Results}

Although the model domain covers both the Baltic Sea and the North Sea, the model results are only presented for the Baltic Sea as our target area $\left(10^{\circ} \mathrm{E}-30^{\circ} \mathrm{E}, 53^{\circ} \mathrm{N}-66^{\circ} \mathrm{N}\right.$; Fig. 1). All experimental cases of N:P ratios were run from 2001 to 2007, but only the results for the last three years (2005-2007) are presented in order to eliminate the impact of initial fields. The surface model results of Chl- $a$, DIN and DIP are compared with observations at three fixed stations in the Baltic Proper for examining seasonal variability (Fig. 2). The model results of Chl- $a$, DIN and DIP are compared with all available observations in the whole Baltic Sea to examine the overall temporal evolution and vertical profile (Fig. 3). As Chl- $a$ is present only in the upper $80 \mathrm{~m}$, the profile of Chl- $a$ is not shown for greater depths (Fig. 3d). The model results of Case NP10 show the best fit with observations in all tested cases. The results of Case NP10 are presented first as a model validation with the calibrated parameters (Table 1). Then the model results of all three cases (NP16, NP10, NP6) are compared to examine the effect of different N/P ratios on algae blooms and nutrient dynamics.

\subsection{Model validation: case NP10}

The model results for Case NP10 (N/P ratio 10:1) are compared with surface data from three offshore stations (Fig. 2). The following observed features are reproduced by the model. Chl- $a$ (Fig. 2a, d, g): the evolution of seasonal growth and decline of phytoplankton is resolved nicely. The growth season of phytoplankton is April to October, when Chl- $a$ concentration is mostly higher than $2 \mathrm{mg} \mathrm{m}^{-3}$ and Chl- $a$ is lower (mostly less than $1 \mathrm{mg} \mathrm{m}^{-3}$ ) from December to February. The observed timing of the spring bloom is also resolved by the model. The main differences between modeled Chl- $a$ and observed data are the magnitude and timing of summerfall peaks. DIN (Fig. 2b, e, h): the model results for DIN capture the observed temporal changes including the decline from high levels during the winter, the duration of depletion, and the recovery to high levels. The difference between the model results and the observed data for DIN is that the winter concentration estimated from the model is lower than the observed concentrations. DIP (Fig. 2c, f, i): the model results for DIP are consistent with observations in the timing of the spring reduction and the fall recovery. The model underestimates the winter concentrations and the reduction in these concentrations during spring blooms. 
A. Chl.a

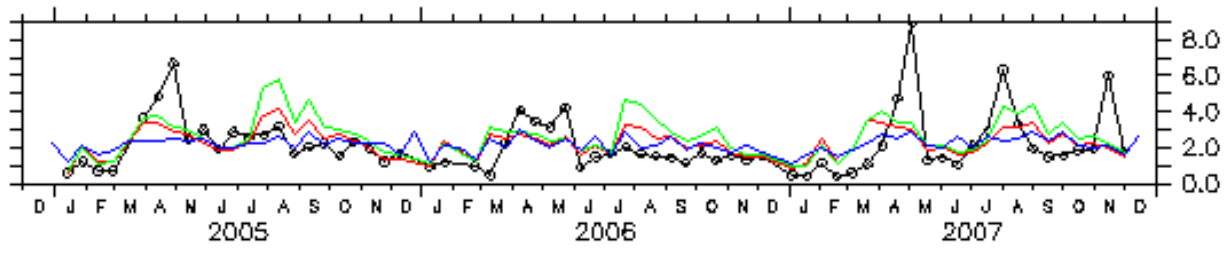

B. DIN

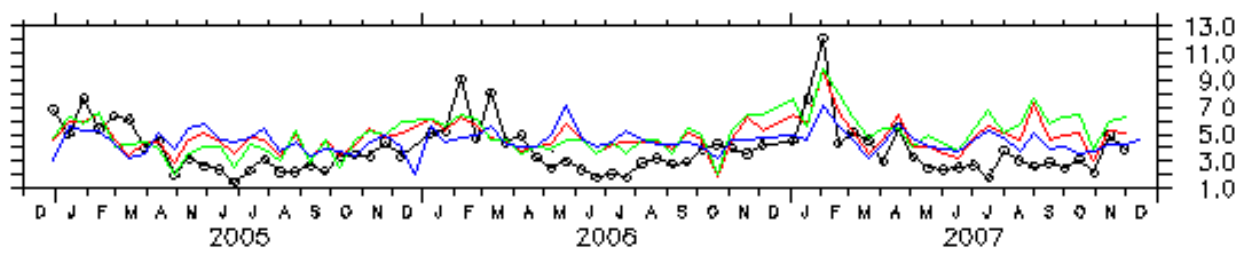

C. DIP

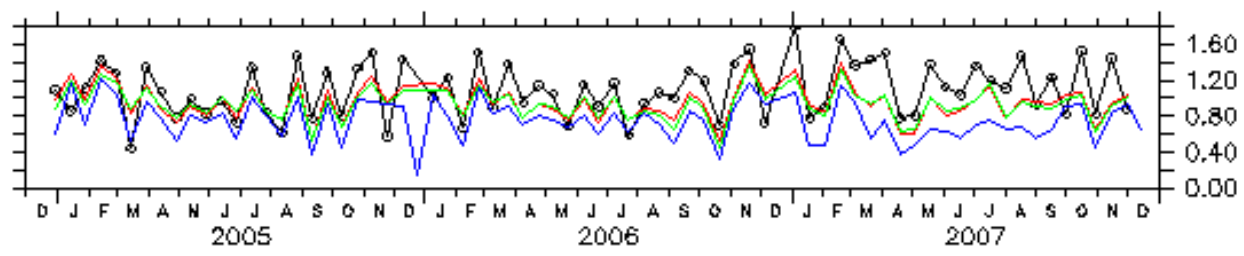

D. Chl.a

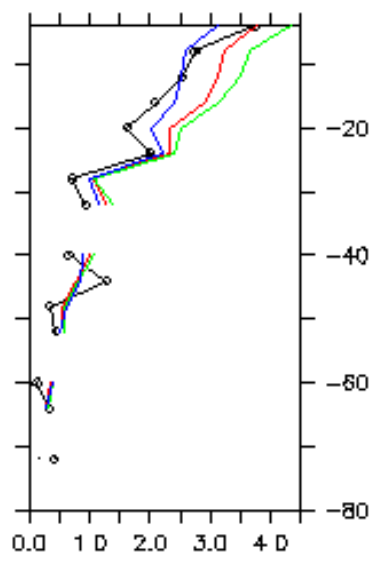

E. DIN

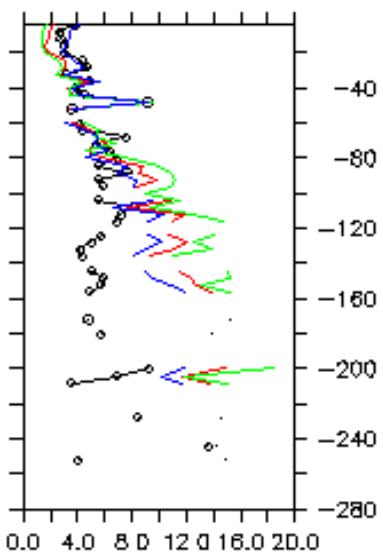

F. DIP

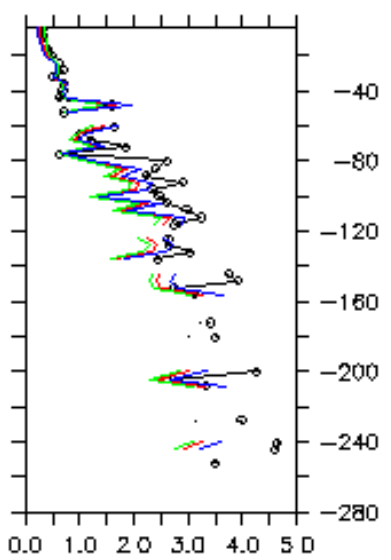

Fig. 3. Comprehensive comparison of model results with all available observations for three experiments. Colors same as in Fig. 2.

The overall performance of the model is demonstrated by comparing observations and model results processed using the comprehensive validation scheme (Fig. 3). Chl- $a$ (Fig. 3a): the model captures the timing of spring blooms and winter declines for temporal changes of Chl- $a$, and the model values are similar to the observed data. However, the model underestimates the magnitude of spring blooms. The vertical profile of observed Chl- $a$ is well-described by the model (Fig. 3d). DIN (Fig. 3b): the model shows a seasonal pattern for DIN that is similar to observations, with high values in winter and low values in summer. Seasonal variations in modeled DIN are smaller than observed values. On average, modeled DIN is higher than observed DIN. DIN below the euphotic layers is generally overestimated by the model. In fact, the vertical profile of model DIN in the euphotic layers is consistent with observations, but higher than observations below the euphotic layers (Fig. 3e). DIP: modeled and observed DIP values are surprisingly consistent in both seasonal pattern (Fig. 3c) and vertical distribution (Fig. 3f), with the model values slightly lower than the observed values. 
A. Total stock of DIN

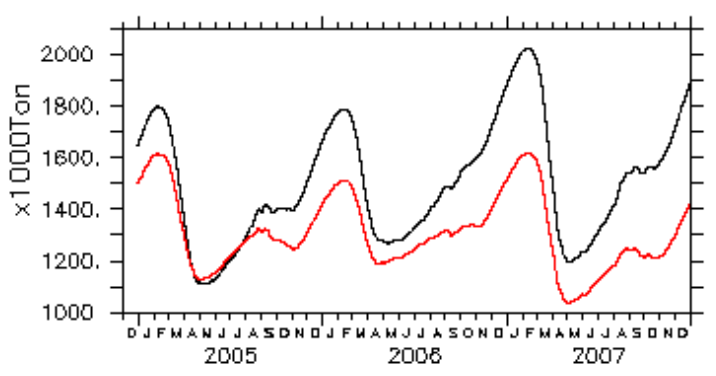

B. Process rates of DIN

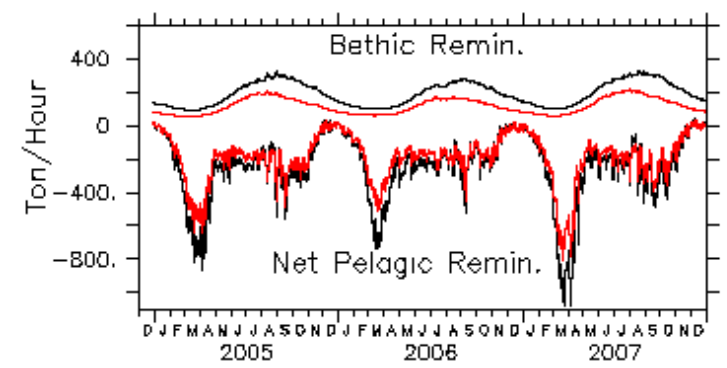

C. Total stock of DIP

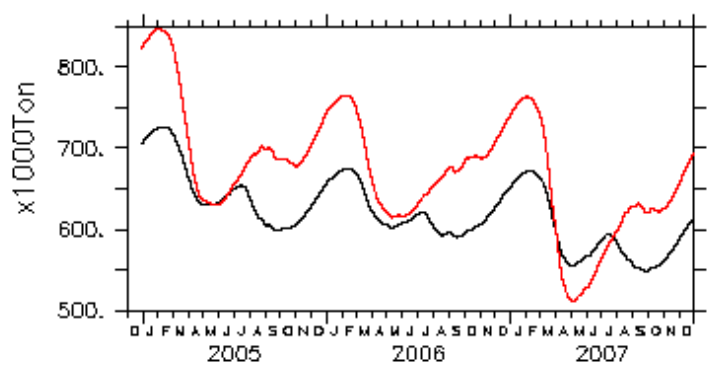

D. Process rates of DIP

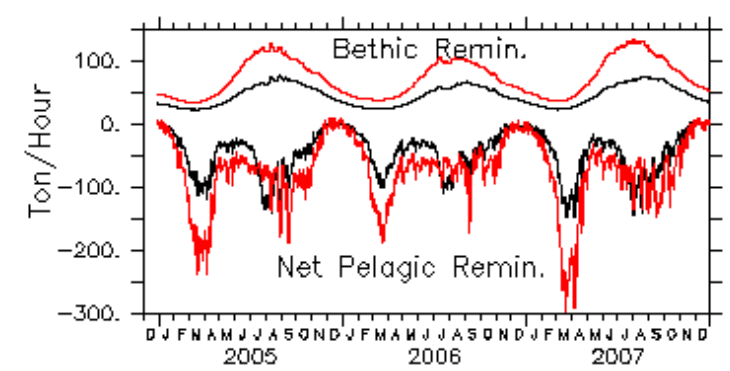

Fig. 4. Comparison between Case NP16 and Case NP6 for nutrient stocks and process rates for Case NP16 (black lines) and Case NP6 (red lines). Units: kiloton for stocks, ton per hour for process rates. DIN stands for dissolved inorganic nitrogen, DIP for dissolved inorganic phosphorus, "Net Pelagic Remin." is the overall nutrient alteration rate caused by biological and biochemical processes in the water column (plotted as negative values), and "Benthic Remin." is the overall nutrient alteration rate from benthic remineralization (plotted as positive values).

\subsection{Comparison of model results among three cases: NP16, NP10, NP6}

When the N/P ratio is lowered from Case NP16 (16:1), to Case NP10 (10:1), to Case NP6 (6:1), model results change continuously (Figs. 2 and 3). The change is first summarized for the surface values at three fixed stations (Fig. 2). The most obvious change for Chl- $a$ is that the overestimation of the peak height in late summer early fall disappears as the N/P ratio decreases (Fig. 2a, d, g). In Case NP10, Chl$a$ peaks in summer-fall are still mostly higher than those in spring, which is inconsistent with the observed Chl- $a$. When the N/P ratio is further lowered (Case NP6), the peak in summer-fall is closer to the observed Chl- $a$. Another change in Chl- $a$ is the decrease in peak heights during the spring bloom. The change for DIN is the decrease in concentration during the winter (Fig. 2b, e, h). DIN in winter is mainly determined by the initial field, the nitrogen fixation, the loses of denitrification and export to the North Sea. Since no other relevant terms have significant difference, the discrepancies among three cases are caused by different nitrogen fixation. In Case NP6, DIN has occasional surplus in summer, e.g., the DIN curve in September 2006 at Stat. 213 (Fig. 2e) and August 2006 at Stat. 271 (Fig. 2h). The most obvious change for DIP is the increase in consumption during the spring bloom (Fig. 2c, f, i). In Case NP16, only a small portion of DIP is consumed during the spring bloom, with the majority consumed in summer-fall. In Case NP6, the majority of DIP is consumed during the spring bloom, resulting in closer correspondence between the curves of modeled and observed DIP.

The global effect on the seasonal pattern of Chl- $a$ from Case NP16 to Case NP6 is similar to the effect on surface Chl- $a$ at three offshore stations in the Baltic Proper, e.g., large decreases in summer-fall peaks and slight decreases in spring peaks (Fig. 3a vs. Fig. 2a, d, g). The global effect on DIN is a decrease in the magnitude of seasonal variation (Fig. 3b vs. Fig. 2b, e, h). The global effect on DIN by changing N/P from 16:1 from 10:1 is not as great as that of changing N/P from 10:1 to $6: 1$. The N/P change from 16:1 to $10: 1$ does not have an obvious effect on the global temporal pattern of DIP (Fig. 3c vs. Fig. 2c, f, i). The N/P change from 10:1 to 6:1 stimulates DIP consumption by phytoplankton so that the global mean DIP decreases. The N/P change from 16:1 to $10: 1$ to $6: 1$ causes the vertical profiles of model results to move progressively closer to observed values for Chl- $a$, DIN and DIP (Fig. 3d, e, f).

Changing the N/P ratio has effects on both the total stocks of DIN and DIP and their major process rates. As the N/P ratio changes continuously from $16: 1$ to $6: 1$, the effects are also continuous. To reduce the complexity, the total stocks and their major processes are displayed for Case NP16 and Case NP6 (Fig. 4). For total stocks, lower N/P ratio leads to lower 
total DIN stock (Fig. 4a) but higher total DIP stock (Fig. 4c). For process rates, lower N/P ratio causes smaller net pelagic remineralization (remineralization plus respiration minus uptake) and benthic remineralization for DIN (Fig. 4b), but larger net pelagic remineralization and benthic remineralization for DIP (Fig. 4d). The reduced DIN remineralization rates (both pelagic and benthic) are caused by the reduced nitrogen fixation. The increased DIP remineralization rates are caused by the initial DIP in benthic detritus which was converted from a fixed nitrogen pool through the N/P ratio.

Comparison of the statistical measures for Chl- $a$, DIN and DIP among three cases is listed in Table 3 for the Baltic Proper $\left(14^{\circ} \mathrm{E}-22^{\circ} \mathrm{E}, 54^{\circ} \mathrm{N}-60^{\circ} \mathrm{N}\right)$ and in Table 4 for the whole Baltic Sea. The model results of Case NP6 are closest to observations in terms of mean value, correlation coefficient and standard deviation among three cases in the Baltic Proper. The modeled Chl- $a$ and DIN of Case NP10 are closest to observations among three cases in the whole Baltic Sea, but Case NP6 gets best DIP.

\section{Discussion}

\subsection{Evidence from the observed data}

The observed "N/P ratio of nutrient alteration" (definition in Sect. 1) for surface water tends to decrease across the Baltic region from Skagerrak to Gotland (Table 2). The N/P ratio of nutrient alteration decreases from 13.7:1 in Skagerrak to 8.3:1 in Arkona, persists below 8.0:1 in the Baltic Proper, and jumps to 27.7:1 in Gulf of Bothnia. We also estimated the N/P ratio of nutrient alteration below the surface (results not shown). The N/P ratio of nutrient alteration does not vary much between the surface and a depth of $20 \mathrm{~m}$, after which it decreases with depth until the bottom of the euphotic layer. Below the euphotic layer, the N/P ratio of nutrient alteration is complicated since in euphotic layers the N/P ratio of nutrient alteration is dominated by the N/P ratio of nutrient uptake; below the euphotic layers this is not necessarily the case. What does the observed N/P ratio of nutrient alteration mean to the N/P ratio of nutrient uptake? Based on its definition, the N/P ratio of nutrient alteration is determined by the biological nutrient uptake, the nutrients supplied by hydrodynamics, river nutrient loadings and atmospheric nutrient deposition. The observed N/P ratio of nutrient alteration serves as a good estimate of the N/P ratio of nutrient uptake for the surface water in the Baltic Proper. Further, it suggests that the N/P ratio of nutrient uptake in the Baltic Proper should be much smaller than the Redfield ratio (16:1). Why?

Based on its definition, the N/P ratio of nutrient alteration compares the nutrients before and after the spring bloom (calculation scheme in Sect. 2.4). Due to the relatively closed nature of the Baltic Proper, the nutrient alteration is mainly related to four processes: atmospheric nutrient deposition, river nutrient loadings, upwelled nutrients, and nutrient up- take. Observed data for DIN and DIP (Fig. 3e and f), show that the DIN/DIP ratio generally decreases with depth. Keeping other nutrient supplies unchanged, a greater contribution of nutrients from upwelling during the spring bloom results in a lower N/P ratio of nutrient uptake. Thus the following estimate does not take the upwelling contribution into account in order to document that the N/P ratio of nutrient uptake is much lower than the Redfield Ratio (16:1).

Mean values of DIN and DIP are $3.28 \mathrm{mmol} \mathrm{m}^{-3}$ and $0.62 \mathrm{mmol} \mathrm{m}^{-3}$ in the Baltic Proper before the spring bloom and $0.19 \mathrm{mmol} \mathrm{m}^{-3}$ and $0.17 \mathrm{mmol} \mathrm{m}^{-3}$ after the bloom. The means are generated by averaging the values at three stations in the Baltic Proper (Table 2). We use $0.124 \mathrm{mmol} \mathrm{m}^{-3} \mathrm{D}^{-1}$ for the atmospheric deposition of DIN (Wulff et al., 2001; Savchuk, 2005). The atmospheric deposition of DIN can only raise the DIN concentration by $0.75 \mathrm{mmol} \mathrm{m}^{-3}$ for the upper $20 \mathrm{~m}$ layer in 120 days (from 1 February to 1 June). The river loadings contribute the same DIN as the atmospheric deposition, according to Wulff et al. (2001) and Savchuk (2005). Thus, the ratio of DIN uptake (3.28$0.19+0.75+0.75)$ to DIP uptake $(0.62-0.17)$ is around $10: 1$. If we consider that the atmospheric deposition and river loadings should be evenly distributed throughout the whole mixed layer $(\sim 40 \mathrm{~m})$, the estimate will definitely be smaller than 10:1. This estimate does not account for the small contribution of DIP from atmospheric deposition and river loadings. This means that a comprehensive estimate will result in a N/P ratio of nutrient uptake smaller than 10:1. Refer to the modeling experiments for a more detailed estimate.

The fact that the N/P ratio of nutrient alteration in the Baltic Sea is largely inconsistent with the Redfield ratio was previously noted by Osterroht and Thomas (2000). They estimated the alterations of dissolved inorganic carbon (DIC), nitrate, and phosphate, due to new production based on data from two cruises (winter of 1994 and summer of 1995). They found that the amount of DIC produced and the uptake of DIN and DIP were inconsistent with Redfield ratios. However, they presumed that the N/P ratio of nutrient uptake was consistent with the Redfield ratio, and attributed the nonRedfield N/P ratio of nutrient alteration to a non-Redfield N/P remineralization of organic material. In other words, they believed that phytoplankton always take up 16 nitrogens with each phosphorus. However, some of those 16 nitrogens may be quickly recycled, and not all 16 nitrogens with each phosphorus can be remineralized at the same time. Their work documents that the N/P ratio of nutrient alteration of net biological pump effects is inconsistent with the Redfield ratio. Our work can support an alternative explanation that the biological N/P ratio of nutrient uptake is inconsistent with the Redfield ratio.

The elemental composition of biology in the Baltic Proper was previously investigated by Shaffer (1987). He calculated the ratio of DO production to DIP consumption based on a natural coordinate conservation approach (Shaffer and Rønner, 1984) using cruise data. The elemental ratio of 
Table 3. Statistic comparison between modeled results and observed data for the whole Baltic Sea.

\begin{tabular}{|c|c|c|c|c|c|c|c|c|c|}
\hline $\begin{array}{l}\text { Statistic measures/ } \\
\text { Cases }\end{array}$ & \multicolumn{3}{|c|}{$\begin{array}{c}\text { Chl- } a \\
\left(\mathrm{mg} \mathrm{m}^{-3} /-\right)\end{array}$} & \multicolumn{3}{|c|}{$\begin{array}{c}\mathrm{DIN} \\
\left(\mathrm{mmol} \mathrm{m}^{-3} /-\right)\end{array}$} & \multicolumn{3}{|c|}{$\begin{array}{c}\text { DIP } \\
\left(\mathrm{mmol} \mathrm{m}^{-3} /-\right)\end{array}$} \\
\hline Number of samplers & \multicolumn{3}{|c|}{7312} & \multicolumn{3}{|c|}{16028} & \multicolumn{3}{|c|}{17302} \\
\hline Mean of observation & \multicolumn{3}{|c|}{2.0} & \multicolumn{3}{|c|}{4.0} & \multicolumn{3}{|c|}{0.92} \\
\hline Standard deviation of observation & \multicolumn{3}{|c|}{2.5} & \multicolumn{3}{|c|}{4.2} & \multicolumn{3}{|c|}{1.11} \\
\hline Case & NP16 & NP10 & NP6 & NP16 & NP10 & NP6 & NP16 & NP10 & NP6 \\
\hline Mean of model & 2.8 & 2.1 & 2.5 & 4.1 & 4.0 & 4.6 & 0.80 & 0.80 & 0.83 \\
\hline Correlation coefficient & 0.36 & 0.39 & 0.34 & 0.41 & 0.42 & 0.38 & 0.82 & 0.83 & 0.83 \\
\hline Standard deviation of model & 1.9 & 1.5 & 1.2 & 5.0 & 4.4 & 4.5 & 0.78 & 0.88 & 1.01 \\
\hline Percentage of bias & 36 & 1 & 21 & 4 & 2 & 17 & -13 & -13 & -9 \\
\hline
\end{tabular}

Abbreviations: Chl for chlorophyll, DIN for dissolved inorganic nitrogen, DIP for dissolved inorganic phosphorus, DO for dissolved oxygen.

Table 4. Statistic comparison between modeled results and observed data for the Baltic Proper.

\begin{tabular}{|c|c|c|c|c|c|c|c|c|c|}
\hline $\begin{array}{l}\text { Statistic measures/ } \\
\text { Cases }\end{array}$ & \multicolumn{3}{|c|}{$\begin{array}{c}\text { Chl- } a \\
\left(\mathrm{mg} \mathrm{m}^{-3} /-\right)\end{array}$} & \multicolumn{3}{|c|}{$\begin{array}{c}\text { DIN } \\
\left(\mathrm{mmol} \mathrm{m}^{-3} /-\right)\end{array}$} & \multicolumn{3}{|c|}{$\begin{array}{c}\text { DIP } \\
\left(\mathrm{mmol} \mathrm{m}^{-3} /-\right)\end{array}$} \\
\hline Number of samplers & \multicolumn{3}{|c|}{3237} & \multicolumn{3}{|c|}{7878} & \multicolumn{3}{|c|}{8664} \\
\hline Mean of observation & \multicolumn{3}{|c|}{1.6} & \multicolumn{3}{|c|}{3.3} & \multicolumn{3}{|c|}{1.4} \\
\hline Standard deviation of observation & \multicolumn{3}{|c|}{1.4} & \multicolumn{3}{|c|}{3.2} & \multicolumn{3}{|c|}{1.3} \\
\hline Case & NP16 & NP10 & NP6 & NP16 & NP10 & NP6 & NP16 & NP10 & NP6 \\
\hline Mean of model & 2.4 & 2.1 & 1.7 & 5.1 & 4.7 & 4.0 & 1.1 & 1.1 & 1.2 \\
\hline Correlation coefficient & 0.52 & 0.53 & 0.54 & 0.47 & 0.47 & 0.50 & 0.88 & 0.88 & 0.87 \\
\hline Standard deviation of model & 1.9 & 1.4 & 1.0 & 5.6 & 5.1 & 4.2 & 0.9 & 1.0 & 1.2 \\
\hline Percentage of bias & 51 & 28 & 3 & 53 & 39 & 19 & -23 & -21 & -15 \\
\hline
\end{tabular}

Abbreviations: Chl for chlorophyll, DIN for dissolved inorganic nitrogen, DIP for dissolved inorganic phosphorus, DO for dissolved oxygen.

$\mathrm{O} 2: \mathrm{C}: \mathrm{N}: \mathrm{P}=159: 130: 14.4: 1$ was derived using the calculated ratio of DO production to DIP consumption. This early approach inevitably simplified the effect from physical processes due to limited computational power, thus the accuracy of the elemental ratios merits further verification. Larsson et al. (2001) analyzed the elemental composition of filamentous cyanobacteria using samples from BY31 (Gotland Sea) in 1994. They found that the C:N and C:P ratios were smaller than Redfield values in spring and started to rise in early June, reaching 5.6:1 (N:C) and 420:1 (C:P) when the biomass of cyanobacteria reached its peak in August and early September.

Although these studies suggested non-Redfield ratios of nutrient uptake for specific species in specific areas, no study has focused on selecting a N/P ratio that is applicable to the entire Baltic Sea in all seasons. This is probably why Redfield ratios were predominantly used in the biogeochemical models for the Baltic Sea (Neumann, 2000; Neumann et al., 2002; Edelvang et al., 2005; Savchuk et al., 2008; Eilola et al., 2009).

\subsection{Support from the modeling experiments}

Comparing Case NP16 and Case NP10 shows that the model results for the latter case are obviously improved for surface Chl- $a$ and DIP in the Baltic Proper, for overall seasonal pattern of Chl- $a$, and for overall vertical profiles of Chl- $a$, DIN and DIP. The most obvious improvement for Chl- $a$ is the disappearance of the overestimated summer-fall peak. The most obvious improvement for DIP is the disappearance of the large DIP surplus after the spring bloom. The improvement for DIN is the reduction of the large bias in deep layers. These improvements can be explained in the causal chain: (1) the Redfield N/P ratio of nutrient uptake caused the surplus of DIP after spring blooms; (2) the excessive DIP stimulated excessive growth of cyanobacteria which can fix atmospheric nitrogen; (3) the overestimate of fixed nitrogen resulted in the export of too much detritus to the deep layer. Are these model biases (large DIP surplus after the spring bloom and unrealistic high peak of summer-fall bloom) characteristic and coherent with the assumption of the Redfield ratio? 


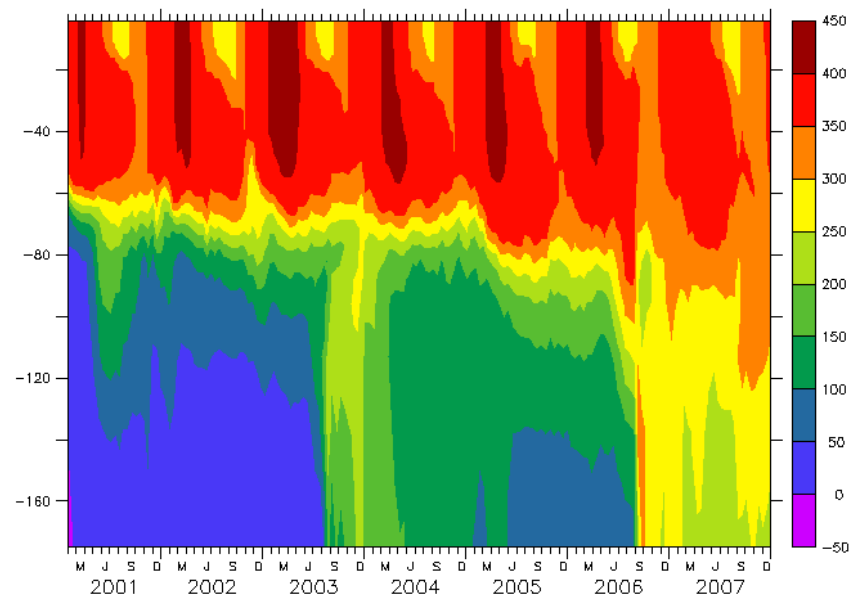

Fig. 5. Temporal evolution of the profile of dissolved oxygen at Station 213, unit: $\mathrm{mmol} \mathrm{m}^{-3}$.

As described in Sect. 3.1, the model validation can be concluded as the model reproduces the observed seasonal variability in the surface layer in the Baltic Proper for Chl- $a$, DIN and DIP (Fig. 2) and the vertical profiles in general (Fig. 3d, e, f). In addition, the statistical measures for overall model performance for Case NP10 (Table 4) appears to be reasonable for this type of models (Neumann et al., 2002; Allen et al., 2007; Neumann and Schernewski, 2008; Lewis and Allen, 2009; Maar et al., 2011). Meanwhile, we notice that the modeled DO is relatively high in lower layers in the Baltic Proper (Fig. 5). The physical model is the core of the operational service system in DMI. Even though the model domain covers both the Baltic Sea and the North Sea, the target area is the Danish Waters. Although it has been validated with the observed data in different focused areas (She et al., 2007a, b; Larsen et al., 2007; Liu et al., 2009), the physical model has not been extensively validated outside of the Danish Waters. The profile of DO at Station 213 shows sudden increases in DO concentration below $100 \mathrm{~m}$ in August 2003 and August 2006 (Fig. 5). However, there are no obvious corresponding increases in the euphotic layers. We believe this is a problem of the circulation model which seems to generate unrealistic ventilations to the relatively isolated deep water. The unrealistic high DO in lower layers can block the denitrification and impact the balance of nitrogen. The potential impact from lower layers where winter mixing cannot reach should have a long term feature, but the N/P ratio of nutrient uptake is mainly a seasonal feature. Nevertheless, it is worthwhile to check whether the characteristic model biases exist in the results of other models under the assumption of the Redfield ratio.

The same problem existed in the model results of Maar et al. (2011) who used ERGOM also. The peak of modeled summer-fall bloom was much higher than the spring peak for stations in the Baltic Sea (Fig. 13 of Maar et al.,
2011), meanwhile, the model DIP was mostly consumed during summer-fall blooms. A similar problem was also found in the model results of Kuznetsov et al. (2008) who used ERGOM but with different circulation model. The peaks of summer-fall blooms were mostly higher than the peaks of spring blooms and the model DIP was also consumed mostly during summer-fall blooms (Fig. 5b and d of Kuznetsov et al., 2008). However, the characteristic model biases were not visible in Neumann et al. (2002). In Neumann's this paper, the seasonal deviation of DIN fit well with the observed data (Fig. 10 in Neumann et al., 2002), but the seasonal deviation of DIP was much smaller than the observed data and model DIP was overall lower the observations (Fig. 12 in Neumann et al., 2002). In other words, the DIP surplus after spring blooms was masked by the fact that the modeled DIP was smaller than the observed data. No detailed modelobservation comparison for seasonal variability for both DIN and DIP was presented in Neumann and Schernewski (2008) where the model was improved with the phosphorus dynamics of iron-phosphate-complexes. All in all, we believe that the model with the Redfield ratio can lead to those characteristic biases.

\subsection{N/P ratio of nutrient uptake in the Baltic Sea}

As stated above, the N/P ratio of nutrient uptake may vary among basins and seasons. Although the N/P ratio of nutrient alteration before and after spring blooms is not identical to the N/P ratio of nutrient uptake, we may use the former as an indicator of the latter. Thus, the observed data (Table 2) indicate that the N/P ratio of nutrient uptake in spring is much smaller than the Redfield ratio in the Baltic Proper, but higher than the Redfield ratio in the Bothnian Bay, and increases from the lowest value in the Baltic Proper to close to the Redfield value in the transitional area between the Baltic Sea and the North Sea. In fall when cyanobacteria are blooming, the N/P ratio of nutrient uptake may increase to up to 4 times the Redfield value (Larsson et al., 2001). Nitrogen fixation and abundant denitrification in anoxic conditions (Shaffer and Rønner, 1984) make it extremely difficult to estimate a fixed N/P ratio of nutrient uptake suitable for the entire Baltic Sea based on observed data. The modeling experiment should be considered as a useful way to estimate this value, even if the model is not able to fully resolve all observed features.

The modeling experiments show that the Redfield N/P ratio is not applicable in all situations and the problems generated by using the Redfield value can be reduced by decreasing the N/P ratio. We think that the N/P ratio 10:1 is best suited for the whole Baltic Sea, based on the results presented here as well as those from additional model runs that are not presented here. As far as the Baltic Proper is concerned, the most accurate N/P ratio could be smaller than 10:1. The modeled phytoplankton peaks in summer-fall are still mostly higher than spring peaks in Case NP10 and the 
DIP surplus after the spring bloom could be further reduced. Thus, the most suitable N/P ratio in the Baltic Proper appears to be closer to $6: 1$. This is also based on the observed N/P ratio of nutrient alteration (Table 2).

Even if a universal N/P ratio of nutrient uptake for different basins and seasons does not actually exist, a fixed value to simplify a real system helps to understand the biogeochemical cycling and balance. In fact, many investigations are based on a fixed N/P ratio for the entire Baltic Sea. For example, Neumann et al. (2002 and 2008) simulated the response of the Baltic ecosystem to a $50 \%$ reduction of riverine nutrient loads and the shift of nitrogen fixation based on the Redfield ratio. Eilola et al. (2009) introduced the internal phosphorus source parameterized with DO and salinity so that the modeled DO and DIP were greatly improved, although DIN was overestimated below euphotic layers (Fig. 8 of Eilola et al., 2009). This study implies the overestimated DIN was likely caused by too much nitrogen fixation, which is similar to the problem in Case NP16 of our model results. As the model limitation using one identical value for two N/P ratios for nutrient uptake and remineralization, the quantitative conclusions are only convincing as a model parameter even though it obviously improves model predictions. Whether this model parameter is consistent with the biological nutrient uptake is worth being further verified with some laboratory investigations or simulations using a more sophisticated model with independent $\mathrm{N} / \mathrm{P}$ ratios for nutrient uptake and remineralization.

\section{Summary}

According to the observed N/P ratio of nutrient alteration before and after spring blooms, a non-Redfield N/P ratio of nutrient uptake in the Baltic Sea is hypothesized. The N/P ratio of nutrient uptake is estimated by using the observed nutrients in combination with other literature estimates on atmospheric deposition and river loadings. This estimate shows that the N/P ratio of nutrient uptake in the Baltic Sea is smaller than the Redfield value. The modeling experiments are implemented to verify the hypothesis and to test for a suitable N/P ratio, by using an ecosystem model ERGOM coupled with the circulation model DMI-BSHcmod. The model results show that using the Redfield value caused too high a DIP surplus after spring blooms and the leftover DIP stimulated excessive Chl- $a$ levels in summer-fall which resulted in too much nitrogen fixation. These problems can be reduced by decreasing the N/P ratio. Similar problems can be found in other model results using the Redfield ratio in the Baltic Sea. This study shows that: (1) the Redfield N/P ratio of nutrient uptake in the Baltic Sea tends to be too high; (2) a lower N/P ratio of 10:1 appears to work better than the Redfield value; and (3) the N/P ratio of nutrient uptake in the Baltic Proper during spring blooms is around 6:1. As the model limitation using one identical value for two N/P ratios of nutrient uptake and remineralization, the quantitative conclusions are restricted to the N/P ratio of the net biological pump effect.

Acknowledgements. This work was supported by European Commission FP6 projects ECOOP (Contract No. 036355), MYCOEAN (Contract No. 218812) and by the Danish Research Council through the project ModREC (FVFP-060683-01). We would like to thank Tracy Shaw for the manuscript preparation, Per Berg for technical assistance with the DMI-BSHcmod model code and the Swedish Meteorological and Hydrological Institute for providing the river data.

Edited by: M. D. Skogen

\section{References}

Allen, J. I., Holt, T. J., Blackford, J., and Proctor, R.: Error quantification of a high-resolution coupled hydrodynamic-ecosystem coastal-ocean model: Part 2. Chlorophyll- $a$, nutrients and SPM, J. Marine Syst., 68, 381-404, 2007.

Anderson, T. R. and Pondaven, P.: Non-redfield carbon and nitrogen cycling in the Sargasso Sea: pelagic imbalances and export flux, Deep-Sea Res. Pt. I, 50, 573-591, 2003.

Arrigo, K. R., Robinson, D. H., Worthen, D. L., Dunbar, R. B., DiTullio, G. R., VanWoertand, M., and Lizotte, M. P.: Phytoplankton community structure and the drawdown of nutrients and $\mathrm{CO}_{2}$ in the Southern Ocean, Science, 283, 365-367, 1999.

Bergström, S.: Development and application of a conceptual runoff model for Scandinavian catchments, Ph.D. thesis., SMHI Reports RHO, No. 7, Norrköping, 1976.

Bergström, S.: The HBV model - its structure and applications, SMHI Reports RH, No. 4, Norrköping, 1992.

Conkright, M. E., Locarnini, R., Garcia, H., O’Brien, T., Boyer, T. P., Stephens, C., and Antonov, J.: World ocean atlas 2001, objective analyses, data statistics and figures, CD-ROM documentation, National Oceanographic Data Center, Silver Spring, MD, 2002.

Dick, S., Kleine, E., Mueller-Navarra, S., Kleine, H., and Komo, H.: The operational circulation model of BSH (BSHcmod) - model description and validation, Berichte des BSH 29/2001, Bundesamt für Seeschifffart und Hydrographie, 1-48, 2001.

Edelvang, K., Kaas, H., Erichsen, A. C., Alvarez-Berastegui1, D., Bundgaard, K., and Jørgensen, P. V.: Numerical modeling of phytoplankton biomass in coastal waters, J. Marine Syst., 57, 13-29, 2005.

Eilola, K., Meier, H. E. M., and Almroth, E.: On the dynamics of oxygen, phosphorus and cyanobacteria in the Baltic Sea: A model study, J. Marine Syst., 75, 163-184, 2009.

Kress, N. and Herut, B.: Spatial and seasonal evolution of dissolved oxygen and nutrients in the Southern Levantine Basin (Eastern Mediterranean Sea): chemical characterization of the water masses and inferences on the N : P ratios, Deep-Sea Res. Pt. I, 48, 2347-2372, 2001.

Kuznetsov, I., Neumann, T., and Burchard, H.: Model study on the ecosystem effect of a variable C:N:P ratio for cyanobacteria in the Baltic Proper, Ecol. Model., 219, 107-114, 2008.

Langner, J., Andersson, C., and Engardt, M.: Atmospheric input of nitrogen to the Baltic Sea basin: present situation, variability 
due to meteorology and effect of climate change, Boreal Environ. Res., 14, 226-237, 2009.

Larsen, J., Høyer, J., and She, J.: Validation of a hybrid optimal interpolation and Kalman filter scheme for sea surface temperature assimilation, J. Marine Syst., 65, 122-133, 2007.

Larsson, U., Hajdu, S., Walve, J., and Elgren, R.: Baltic Sea nitrogen fixation estimated from the summer increase in upper mixed layer total nitrogen, Limnol. Oceanogr., 46, 811-820, 2001.

Lewis, K. and Allen, J. I.: Validation of a hydrodynamic-ecosystem model simulation with time-series data collected in the western English Channel, J. Marine Syst., 77, 296-311, 2009.

Liu, Y., Zhu, J., She, J., Zhuang, S., Fu, W., and Gao, J.: Assimilating temperature and salinity profile observations using an anisotropic recursive filter in a coastal ocean model, Ocean Model., 30, 75-87, 2009.

Maar, M., Møller, E. F., Larsen, J., Kristine, S. M., Wan. Z., She, J., Jonasson, L., and Neumann, T.: Ecosystem modeling across a salinity gradient from the North Sea to the Baltic Sea, Ecol. Model., 222, 1696-1711, 2011.

Minster, J.-F. and Boulahdid, M.: Redfield ratios along isopycnal surfaces - a complementary study, Deep-Sea Res., 34, 19812003, 1987.

Moore, J. K., Doney, S. C., Kleypas, J. A., Glover, D. M., and Fung, I. Y.: An intermediate complexity marine ecosystem model for the global domain, Deep-Sea Res. Pt. II 49, 403-462, 2002.

Neumann, T.: Towards a 3d-ecosystem model of the Baltic Sea, J. Marine Syst., 25, 405-419, 2000.

Neumann, T. and Schernewski, G.: Eutrophication in the Baltic Sea and shifts in nitrogen fixation analyzed with a 3D ecosystem model, J. Marine Syst., 74, 592-602, 2008.

Neumann, T., Fennel, W., and Kremp, C.: Experimental simulations with an ecosystem model of the Baltic Sea: a nutrient load reduction experiment, Global Biogeochem. Cy., 16, 7(1)-7(19), 2002.

Osterroht, C. and Thomas, H.: New production enhanced by nutrient supply from non-Redfield mineralisation of freshly produced organic material, J. Marine Syst., 25, 33-46, 2000.
Redfield, A. C.: On the proportions of organic derivations in sea water and their relation to the composition of plankton, in: James Johnson Memorial Volume, edited by: Daniel, R. J., University Press of Liverpool, 177-192, 1934.

Savchuk, O. P.: Resolving the Baltic Sea into seven subbasins: N and P budgets for 1991-1999, J. Marine Syst., 56, 1-15, 2005.

Savchuk, O. P., Wulff, F., Hille, S., Humborg, C., and Pollehne, F.: The Baltic Sea a century ago - a reconstruction from model simulations, verified by observations, J. Marine Syst., 74, 485494, 2008.

She, J., Berg, P., and Berg, J.: Bathymetry effects on water exchange modeling through the Danish Straits, J. Marine Syst., 65, 450 459, 2007a.

She, J., Høyer, J., and Larsen, J.: Assessment of sea surface temperature observational networks in the Baltic Sea and North Sea, J. Marine Syst., 65, 314-335, $2007 \mathrm{~b}$.

Shaffer, G.: Redfield ratios, primary production, and organic carbon burial in the Baltic Sea, Deep-Sea Res. Pt. I, 34, 769-784, 1987.

Shaffer, G. and Rønner, U.: Denitrification in the Baltic proper deep water, Deep-Sea Res., 31, 197-220, 1984.

Touratier, F., Field, J. G., and Moloney, C. L.: A stoichiometric model relating growth substrate quality $(\mathrm{C}: \mathrm{N}: \mathrm{P}$ ratios) to $\mathrm{N}: \mathrm{P}$ ratios in the products of heterotrophic release and excretion, Ecol. Model., 139, 265-291, 2001.

Wong, C. S., Waser, N. A. D., Nojiri, Y., Whitney, F. A., Page, J. S., and Zeng, J.: Seasonal cycles of nutrients and dissolved inorganic carbon at high and mid latitudes in the North Pacific Ocean during the Skaugran cruises: determination of new production and nutrient uptake ratios, Deep-Sea Res. Pt. II, 49, 5317-5338, 2002.

Wulff, F., Rahm, L., Hallin, A.-K., and Sandberg, J.: A nutrient budget model of the Baltic Sea, in: A System Analysis of the Baltic Sea, edited by: Wulff, F., Rahm, L., and Arsson, P., SpringerVerlag, Berlin, 353-372, 2001. 